\title{
Perspectivas em (in)formação: tendências e tensões entre abordagens físicas, cognitivistas e emergentes
}

\author{
Perspectives on (in)formation: trends and tensions among \\ physical, cognitivist and emergent approaches
}

Luiz Fernando de Barros CAMPOS'

Ludmila Salomão VENÂNCIO²

\section{RESUMO}

Apresenta uma visão epistemológica e histórica das abordagens físicas, cognitivistas e emergentes no campo da Ciência da Informação, adotando o conceito de abordagem de Wersig em detrimento da concepção de paradigma. Expõe as polarizações entre diversas conceituações de informação e ilustra como problemas práticos do campo foram solucionados ou temas de pesquisa desenvolvidos com base nos modelos adotados e nas ligações transdisciplinares efetuadas pelos diferentes tipos de abordagens, incluindo a análise de domínio e a cognição situada. Conclui reconhecendo a atual premência da integração das várias abordagens, da tradução e fundamentação dos conceitos utilizados, da diversificação metodológica e de um viés pragmático que foque os problemas comuns e soluções adotadas no campo e considere os aspectos sociais, históricos e epistemológicos nos diversos domínios.

Palavras-chave: Ciência da Informação; abordagens físicas; abordagens cognitivistas; análise de domínio; cognição situada; paradigma.

\section{A B S T R A C T}

This article presents an epistemological and historical view of the physical, cognitivist and emergent approaches in the field of Information Science, adopting Wersig's concept of approach, instead of the concept of paradigm. It shows the polarizations occurring among the diverse conceptualizations in Information Science, and it illustrates how practical problems were solved in the field. It also indicates how research subjects were developed, grounded on adopted models and transdisciplinary connections made by the different kinds of approaches, including the domain analysis and the situated cognition. The article concludes pointing out to the need for integrating the various approaches and translating instrumental concepts and/or laying their foundations. The conclusion also indicates the need for methodological diversification and for a pragmatic view, which should focus at the ordinary problems and adopt solutions in the field that would take into account the social, historical, and epistemological dimensions of the diverse domains.

Keywords: Information Science; physical approaches; cognitivist approaches; domain analysis; situated cognition; paradigm.

\footnotetext{
' Mestre em Ciência da informação, Escola de Ciência da Informação, Universidade Federal de Minas Gerais. Avenida Presidente Antônio Carlos, 6627, Pampulha, 31270-901, Belo Horizonte, MG, Brasil. Correspondência para/Correspondence to: L.F.B. CAMPOS. E-mail: <lfbcampos@gmail.com>.

${ }^{2}$ Mestre em Ciência da Informação, Escola de Ciência da Informação, Universidade Federal de Minas Gerais. Belo Horizonte, MG, Brasil.E-mail: <salomao@eci.ufmg.br>.

Recebido em 30/11/2006 e aceito para publicação em 22/5/2007.
} 


\section{NTRODUÇÃ O}

Nos anais da Conferência Internacional do $20^{\circ}$ aniversário do Departamento de Estudos de Informação da Universidade de Tampere, Finlândia, 1991 (editados por Vakkari; Cronin, 1992), foram publicados vários artigos abordando a Ciência da Informação sob a perspectiva de paradigmas, notadamente os de Ellis (1992) e Capurro (1992). Posteriormente, Capurro (2003a), no V Encontro Nacional de Pesquisa em Ciência da Informação, apresentou uma visão geral da evolução da Ciência da Informação identificando um escopo de investigação epistemológica com base no mesmo conceito de paradigma.

Tais autores partem da concepção original de paradigma de Kuhn. Segundo esse autor, o paradigma, de um lado, indica toda a "constelação de crença, valores, técnicas partilhadas pelos membros de uma comunidade determinada". Por outro lado, denota um tipo de elemento dessa constelação, isto é, "[...] as soluções concretas de quebra-cabeças que, empregadas como modelos ou exemplos, podem substituir regras explícitas como base para solução dos restantes quebracabeças da ciência normal" (Kuhn, 2000, p.218).

Masterman (1970) efetuou um estudo crítico sobre a obra de Kuhn, na qual identificou 21 diferentes significados do termo paradigma, destacando o seu emprego em sentido metafísico, sociológico, e relativo a generalizações simbólicas ou valores. Outras vezes, o termo assume um sentido de paradigma-artefato ou paradigma-construto considerado exemplar. Isso significa que o paradigma é concebido como uma analogia crua, que viabiliza diversos modos de ver, como modelos, desenhos, esquemas de seqüências de palavras, ou uma combinação desses. Ao mesmo tempo, os paradigmas devem ser suficientemente originais e instigadores de novas questões e interpretações, que permitam o desenvolvimento da teoria e da pesquisa em um campo.

Wersig (1993) criticou a análise da Ciência da Informação sob essa perspectiva de paradigmas, remetendo à conferência internacional ocorrida na Finlândia, em 1991. Para o autor, a visão paradigmática tem conduzido a trabalhos que não são realmente motivados por mudanças de paradigmas ou por competição entre eles. A seu ver, de um modo mais realista, as alternativas aos paradigmas seriam abordagens direcionadas a questões específicas e suas resoluções.
As diferentes abordagens caracterizam-se pela transdisciplinaridade, pela ênfase em determinado modelo ou esquema e pelo foco nos problemas práticos da área, nas soluções adotadas e nos estudos empíricos.

Assim, adota-se aqui a conceitualização de abordagens proposta por Wersig (1993), consideradas como pontos de entrada para um estudo epistemológico e histórico da Ciência da Informação. A ênfase é colocada nas possibilidades descritivas e analíticas que a utilização do conceito origina. Mantém-se o sentido de exemplaridade existente na concepção de paradigma ao se admitir o caráter de modelos ou esquemas presente no conceito de abordagem, mas acentuam-se suas complementaridades. Portanto, o objetivo do presente artigo é apresentar uma visão panorâmica de algumas abordagens emblemáticas (físicas, cognitivistas, emergentes) do campo da Ciência da Informação, expondo as diferentes conceitualizações de informação (que oscilam de informação como coisa, até definições mais fluidas que valorizam os aspectos sociais, comunicacionais, vivenciais e situacionais) e ilustrando como os problemas práticos do campo foram solucionados ou os temas de pesquisa desenvolvidos com base nos modelos adotados e nas ligações transdisciplinares efetuadas.

Definições usuais da Ciência da Informação abarcam componentes tecnológicos e de construção de sistemas de informação (Saracevic, 1996). De modo semelhante a outros autores, Le Coadic (1996, p.26) declarou que "[...] a Ciência da Informação tem também como objeto a concepção de produtos e sistemas que permitam a construção, comunicação, armazenamento e uso da informação". Assim, aqui se posicionam as abordagens físicas e cognitivistas frente à prática de desenvolvimento de sistemas de recuperação de informação, por meio da exposição de dois modelos: o experimento de Cranfield e o sistema de recuperação de informação baseado em estados anômalos de conhecimento, de Belkin; Oddoy; Brooks (1982a, 1982b). Enfatizam-se os sistemas de recupe-ração, pois estes incorporam funções consideradas "clássicas" da Ciência da Informação, como a representação, o armazenamento e a busca de informações. Entre as abordagens emergentes consideradas no sentido aqui assumido, de orientação pragmática e social, duas são examinadas. Destaca-se a cognição situada, a qual transcende as concepções fundadoras de representação e gap cognitivo (a insuficiência cognitiva) das abordagens cognitivistas, tendo aqui descritas algumas de suas 
aplicações empíricas atuais. A segunda abordagem emergente analisada é a análise de domínio, valorizadora do percurso histórico, das dimensões sociais e dos aspectos epistemológicos das disciplinas e campos científicos e das comunidades discursivas.

Subjaz, ainda, à exposição, a necessidade de estabelecer relacionamentos e conexões entre as diversas abordagens, sem supor uma periodização estrita ou instituição de perspectivas estanques. Assim, a apresentação das abordagens segue a lógica de evidenciar a ciência em formação, em seu processo não-linear de fundação e reconfiguração. Para tanto, o artigo estrutura-se em três seções principais tratando de cada tipo de abordagens; tais seções estão intermediadas por outras que procuram estabelecer semelhanças e contrastes entre as abordagens (transições cognitivista e pragmática). Nos comentários finais, com base na exposição precedente, é criticado o tratamento dos conceitos multidisciplinares no campo da Ciência da Informação, reconhecendo a necessidade de sua tradução e fundamentação, assim como a premência da integração das várias abordagens, da diversificação metodológica e de um viés pragmático que foque os problemas comuns e soluções adotadas no campo e considere os aspectos sociais, históricos e epistemológicos nos diversos domínios.

\section{ABORDAGENS FíSICAS}

As abordagens físicas relacionam-se diretamente com a teoria da informação de Shannon e Weaver e com a cibernética de Norbert Wiener. Há também uma forte conexão com o esquema fonte-transmissor-sinalruído-receptor-destinatário, no sentido de que haveria uma entidade física ou energética efetivamente transmitida de uma fonte ao destinatário final. Shannon (1948, p. 1) assim se pronunciou:

Esses aspectos semânticos da comunicação são irrelevantes para o problema de engenharia. $\bigcirc$ aspecto significativo é que a mensagem é selecionada de um conjunto de possíveis mensagens. [...] Se o número de mensagens no conjunto é finito, então esse número ou qualquer função monotônica desse número podem ser considerados uma medida da informação produzida.

Os aspectos do sentido da informação são desconsiderados para o problema de engenharia delimitado. Na teoria da informação (ou teoria matemática da comunicação) as mensagens ou sinais são transmitidos e a informação é quantificada como uma medida de um repertório de signos colocados à disposição e escolhidos pelo emissor, que devem, necessariamente, ser (re)conhecidos pelo receptor. A informação, vista como uma função de probabilidade associada ao ruído no canal, aumenta a incerteza e é a mensagem que irá reduzi-la. A entropia está ligada a essa probabilidade de escolha, à imprevisibilidade e à desorganização. A redundância é a repetição utilizada para garantir o perfeito entendimento. Desse modo, o objetivo é o estudo da comunicação de informação através de canais mecânicos, medindo-se a quantidade de informação passível de transmissão e evitando-se que ocorram as distorções possíveis na propagação (Araújo, 2003).

A comunicação é vista não como um processo, mas como sistema. Quando a Ciência da Informação apropriou-se dos conceitos da teoria, a natureza bruta da analogia adotada ficou claramente evidenciada: há uma relação entre a veiculação física de um sinal (cujos aspectos semânticos e pragmáticos foram explicitamente descartados por Shannon) e a transmissão da mensagem.

A teoria da informação, definindo um modelo de fenômeno comunicativo, teve profunda repercussão nos estudos de comunicação de massa nas décadas de 20 a 50 e nas décadas iniciais de construção do campo da Ciência da Informação. Gradativamente, nos estudos de comunicação e informação, passou-se a considerar a influência de outros fatores, como as características psicológicas dos receptores, a organização das mensagens, as redes de relações interpessoais, os elementos extramídia e o uso que as pessoas fazem destes elementos.

\section{Experiência de Cranfield}

Considera-se usualmente que a série de testes executadas pelo Cranfield Institute of Technology, em 1957, constituiu o começo da pesquisa de recuperação de informação como uma área do campo da Ciência da Informação e instituiu uma metodologia, além de gerar a tendência a uma abordagem empírica e experimental bem definida, até hoje de reconhecida utilidade e importância. Ao mesmo tempo, esses experimentos são emblemáticos das possibilidades de 
soluções advindas dos princípios incorporados nas abordagens físicas.

As experiências de Cranfield consistiam em criar um banco de informações bibliográficas (a coleção de teste), idealizar um conjunto de questões que possibilitassem a consulta ao banco e, com base em julgamentos efetuados por especialistas humanos, determinar a relevância para cada par de questões e documentos.

Desse modo, cada documento da coleção era antecipadamente conhecido como relevante ou não relevante para a questão (sendo a relevância concebida como a relação entre documento e questão, abstraídos os demais fatores). O sucesso do processo de recuperação era, então, medido pelas relações entre documentos relevantes ou não, e pelos documentos recuperados ou não, dando-se ênfase aos aspectos de revocação, precisão e medidas quantificadas.

Ellis (1992) tentou determinar se os experimentos de Cranfield teriam natureza paradigmática, considerando dois diferentes pontos: por um lado, indagando se os experimentos teriam as características de concretude que possibilitariam sua utilização como uma analogia e, por outro lado, examinando quaisquer comparações que tenham sido efetuadas durante o projeto e realização dos testes. Analisando escritos do diretor do projeto, Cyril Cleverdon, e a linguagem empregada, o autor notou que a perspectiva adotada caracterizava-se como física ou mecânica, ao invés de psicológica. Havia, por exemplo, a comparação com experimentos de aviação realizados em túneis de vento. A linguagem de indexação era concebida como um amálgama de dispositivos (módulos) de linguagens de indexação, assim como eram concebidos os sistemas mecânicos, caracterizados como uma contribuição de suas diferentes partes.

\section{A TRANSIÇÃO COGNITIVISTA}

As abordagens físicas têm como princípio o fornecimento de uma informação específica no atendimento a uma questão bem determinada de um usuário genérico, conhecido (ou delimitado) a priori. Em oposição, as abordagens cognitivistas convergem para esse usuário, ao considerar a alteração de seus estados cognitivos resultantes de um processo de transmissão e apreensão da informação.
Como afirmam Favier e Martin-Juchat (2002, p. 257-258) houve uma transição caracterizada pela transferência da ênfase, dos sistemas para os usuários individuais:

[...] desde seu início, a Ciência da Informação desenvolveu estudos de usuários, mas atingiu, talvez tardiamente, o que pode ser denominado uma mudança de paradigma: a passagem do paradigma "sistema" (visto como a correspondência entre uma pesquisa e a representação de documentos) ao paradigma "usuário" (visto como a correspondência entre o sistema e a necessidade de informação).

De certa forma, a própria passagem das abordagens físicas para as cognitivistas sinaliza uma reação inicial que se manifesta com a criação de um "objeto mental". A informação-coisa é agora vista como uma imagem mental. Na literatura do campo, surgem inúmeras referências a Popper, com seu terceiro mundo dos objetos inteligíveis (formulações lingüísticas compartilháveis, teorias, modelos e postulados de conhecimento sobre o mundo), ou à teoria platônica das idéias autônomas, como ocorre em Miranda (2002).

Também nessa literatura passa a ser incorporada, com maior intensidade, a idéia de conhecimento. A transmissão e o processamento da informação possibilitariam o aprimoramento das estruturas de conhecimento do usuário individual. Outra idéia mais fortemente explorada é a de representação. O mundo externo seria representado mentalmente pelo usuário através de uma série de imagens e os sistemas de recuperação tenderiam a efetuar uma junção das estruturas mentais do construtor das bases de dados e das estruturas do usuário.

É interessante observar que a idéia de bestmatching é comum às abordagens físicas e cognitivistas. No caso das abordagens físicas, tende-se a considerar a informação como algo concreto que vai de encontro a uma necessidade específica a ser suprida. Já nas abordagens cognitivistas, a informação é usualmente compreendida como uma imagem que procura sanar um particular estado de conhecimento deficiente do usuário.

Vê-se que o cognitivismo, ao polarizar a informação no domínio da subjetividade, tendeu a ampliar o conceito de recuperação da informação das abordagens físicas. Ao mesmo tempo, dada a ênfase no sujeito cognoscente, as abordagens cognitivistas 
seguem atreladas ao paradigma moderno de representação (González de Gómez, 2002).

\section{ABORDAGENS COGNITIVISTAS}

A partir da década de 70, algumas das direções mais produtivas dos estudos informacionais resultaram das abordagens da informação sob a perspectiva cognitivista. As expressões mais significativas dessas abordagens são os Estados Anômalos do Conhecimento de Belkin; Oddy; Brooks (1982a, 1982b) e o mentalismo de Brookes (1980).

Em geral, as abordagens cognitivistas pressupõem a existência de um mundo externo, cujas características e relações podem ser captadas e representadas na mente do indivíduo. $O$ indivíduo, então, com as capacidades cognitivas adequadas, age com base nessas representações de atributos relevantes do mundo e seus modos de relacionamento, a fim de resolver problemas que the são apresentados.

Exemplifica essa perspectiva, amplamente difundida e aceita por muitos autores de abordagens cognitivistas, a visão de De Mey (1980 p.48), na qual o processamento da informação desempenhado pelo sistema simula o processamento mental que o indivíduo realiza para entender o mundo. Segundo esse autor "[...] qualquer processamento de informação, perceptual ou simbólico, é mediado por um sistema de categorias ou conceitos que, para o dispositivo de processamento da informação, constituem o modelo de seu mundo."

Brookes, um dos primeiros proponentes da visão cognitivista na Ciência da Informação, formaliza seu conceito de informação baseado no conhecimento objetivo (conhecimento inteligível do mundo 3) desenvolvido por Popper. Para Brookes (1980, p.131), o conhecimento "[...] é uma estrutura de conceitos ligados por suas relações e informação [é] como uma pequena parte dessa estrutura". A estrutura de conhecimento, que pode ser tanto subjetiva quanto objetiva, é transformada pela informação em uma nova estrutura de conhecimento. Tal mudança pode ser expressa pela equação $\mathrm{K}[\mathrm{S}]+\Delta \mathrm{I}=\mathrm{K}[\mathrm{S}+\Delta \mathrm{S}]$, na qual a estrutura de conhecimento $K[S]$ é modificada para uma nova estrutura $\mathrm{K}[\mathrm{S}+\Delta \mathrm{S}$ ] pela informação $\Delta \mathrm{l}$, e $\Delta \mathrm{S}$ indica o efeito da mudança. Nesse contexto, conhecer é compreendido como um ato de interpretação ou assimilação da informação pelas estruturas mentais do indivíduo que percebe o meio durante uma interação. A produção do conhecimento se dá, então, pela reconstrução das estruturas mentais do indivíduo através da sua competência cognitiva, ou seja, pela modificação em seu estoque mental de conhecimento. Brookes (1980, p. 131) expressou o ponto da seguinte forma: "[...] a absorção da informação em uma estrutura de conhecimento pode causar não apenas um acréscimo, mas algum ajuste na estrutura, bem como uma mudança nas relações entre dois ou mais conceitos já admitidos".

\section{Os estados anômalos do conhecimento de Belkin}

O modelo de recuperação de informação proposto por Belkin; Oddoy; Brooks (1982a, 1982b) é exemplar da maneira de encarar os problemas empíricos e das expectativas de suas resoluções sob o ponto de vista cognitivista. Os autores consideram a natureza do estado do conhecimento do usuário como fenômeno básico para a compreensão do processo de recuperação da informação. Nesta perspectiva, o usuário é considerado um sujeito cognoscente que utiliza os sistemas de recuperação ao reconhecer uma anomalia ou um estado de conhecimento inadequado ou incoerente com relação a algum assunto ou problema, denominado estado anômalo do conhecimento (anomalous state of knowledge).

Apesar de identificar seu estado de conhecimento inadequado, o usuário é incapaz de especificar - que é necessário para transpor essa anomalia e é incoerente requerer que ele expresse diretamente suas necessidades de informação, uma vez que é exatamente o "gap no conhecimento" que o direcionou ao sistema. Embora as necessidades de informação não sejam, a princípio, precisamente especificáveis, como argumentam os autores, elas só podem ser esclarecidas através do relato da situação problemática experimentada pelo usuário, que retrata adequadamente os objetivos, os problemas e os estados de conhecimento do indivíduo sobre a situação específica.

Assim, as narrativas de problemas, fornecidas pelos usuários, são utilizadas pelo sistema de informação para recuperar, de um corpus de textos, um texto que deva ser apropriado para resolver a anomalia. O documento recuperado é visto como a representação de um estado coerente de conhecimento, enquanto que a 
pergunta ou texto relacionado com uma necessidade de informação é a representação de um estado de conhecimento inadequado. A informação, então, se constitui na relação entre um corpus de textos disponíveis e um outro texto que expressaria um estado de conhecimento anômalo.

Representadas as necessidades de informação, bastaria, então, especificar os mecanismos e estratégias de recuperação, diversos para cada tipo de estado anômalo de conhecimento. Assim, os autores propõem um modelo de sistemas de recuperação interativo que determina as representações de estados de conhecimento anômalos, tendo por base as necessidades de informação. O sistema constrói uma representação do conhecimento do usuário através de redes de associações entre palavras identificadas nas declarações narrativas do problema, examina essa estrutura, interpreta as características estruturais das representações para determinar os estados anômalos do conhecimento, e pesquisa as descrições de documentos estruturados com o objetivo de solucionar a anomalia. $\bigcirc$ usuário, então, avalia os documentos recuperados e essa avaliação é utilizada, pelo sistema, para determinar as adequadas modificações nas representações das necessidades do usuário, assim como a troca da estratégia para a definição das características significativas do mecanismo de busca adotado.

$\bigcirc$ componente interativo é um aspecto crítico do sistema. Cada ciclo do processo de recuperação da informação depende da avaliação realizada pelo usuário dos ciclos anteriores, tendo em vista que a anomalia e a percepção do indivíduo com relação ao problema são modificadas a cada interação com o sistema.

Em resumo, as funções básicas do sistema de recuperação de informação podem ser esquematicamente expressas pelas fases a seguir: (1) explicitação, por escrito, do problema do usuário; (2) análise estrutural da explicitação do problema através de um programa de análise de texto; (3) escolha da estratégia de recuperação de acordo com o tipo de estado anômalo; (4) apresentação, para o usuário, do resumo dos documentos recuperados, junto com a explicação da escolha do texto e a exposição da estratégia adotada pelo mecanismo de busca; (5) diálogo estruturado entre o sistema e o usuário para inferir a avaliação do usuário em relação à escolha do método, à adequação do documento ao problema, e/ou à eventual mudança da necessidade de informação; (6) finalização do processo de recuperação de informação, caso haja satisfação do usuário, ou modificação de acordo com a avaliação do usuário, implicando retorno à análise estrutural do problema (fase 2) ou escolha da nova estratégia de recuperação (fase 3).

\section{A TRANSIÇÃO PRAGMÁTICA}

As abordagens cognitivistas, ao enfatizar a natureza individual das estruturas cognitivas dos usuários, costumam elaborar modelos operacionais e inferenciais a partir de uma generalização de regularidades psicológicas do sujeito cognoscente e de seu comportamento, e tendem a isolá-los das relações sociais e dos contextos de ação nos quais estão inseridos, relegando a um nível numênico os processos sociais de produção, distribuição e troca de informação. Essa visão reducionista das abordagens cognitivistas foi criticada por Capurro (2003a, p.7), ao afirmar:

Os limites do paradigma cognitivo apóiam-se precisamente na metáfora de considerar a informação como algo separado do usuário, localizado em um mundo numênico, ou de ver o usuário, se não exclusivamente, em primeiro lugar como sujeito cognoscente, deixando de lado os condicionamentos sociais e materiais do existir humano.

Uma abordagem mais pragmática considera a informação como um construto social, historicamente constituída nas interações dos sujeitos com outros sujeitos. Neste sentido, Ingwersen (1999, p.14) pronunciou-se: "[...] as estruturas e estados cognitivos atuais de um indivíduo são determinados pelas experiências adquiridas ao longo do tempo, em um contexto cultural e social através da interação social".

Segundo Capurro (2003a), partiu-se de abordagens puramente cognitivistas (Brookes e Belkin) para tendências que, gradativamente, levavam em conta os fatores sociais no cognitivismo (Ingwersen, por exemplo). $\bigcirc$ próprio Belkin, no começo da década de 90, embora ainda mantendo-se fiel às suas premissas cognitivistas, sinalizou a tendência de discernir dois níveis de análise dos processos cognitivos, em sua relação com a informação: um micro-nível, de análise de um ato pontual de cognição, e um macro-nível, de identificação das metas e objetivos do usuário e de um "domínio da representação" (González de Gómez , 2002). 
As abordagens pragmáticas são nitidamente influenciadas pela filosofia de tradição fenomenológica e pela teoria dos jogos de linguagem de Wittgenstein. A transição pragmática engloba diversas expressões. Uma delas é o ponto de vista da hermenêutica e da retórica (Capurro, 2000, 2003b), que só admite o conhecimento em um horizonte de pré-compreensão em um mundo comum, cujo partilhamento temático e situacional constitui informação, e que destaca o papel da interpretação, dada justamente a impossibilidade de diferenciar informação de desinformação. Outra expressão é a análise dos discursos, metodologia utilizada, por exemplo, em Frohmann (1992), para criticar o ponto de vista cognitivista na Ciência da Informação.

A pragmática está relacionada a uma prática e a uma necessidade (na origem grega da palavra, temse o significado de "ter de viver com"). Há uma coincidência com os preceitos mais realistas sugeridos por Wersig (1993), que focam os problemas práticos e as soluções comumente adotadas no campo. Capurro (1992) situou a transição pragmática na década de 80 com a abordagem comportamental de Roberts, do "homem informacional", ou a teoria das "ações informacionais" de Wersig, onde os atores estão inseridos em situações problemáticas. De acordo com esta última teoria, é a intencionalidade do ator que faz uma ação significativa. Cada sistema de agenciamento da ação tem diferentes potencialidades ou disposições que caracterizam diversos espaços de realização da ação. A ação da informação ocorre em um espaço de racionalização e um espaço de provisão, onde se buscam recursos argumentativos para lidar com situações problemáticas.

A teoria dos ambientes informacionais de Taylor $(1982,1991)$ assume um posicionamento similar, ao considerar os determinantes situacionais dos grupos de trabalho, das classes de problemas, dos ambientes de trabalho e das soluções de problemas. Essa estruturação do ambiente de uso da informação, constitui um método sistemático para analisar as necessidades de informação de uma organização: (1) identificar os grupos de usuários de informação e os pressupostos e atitudes comuns que influenciam as necessidades de informações, (2) diagnosticar os tipos de problemas mais freqüentes que usualmente preocupam determinado grupo de pessoas, (3) examinar as características físicas e sociais do ambiente social e de trabalho e (4) determinar os modos de solução habitualmente considerados pelos usuários.
Ao ver de Capurro (1992), a informação não é mais o produto final de um processo de representação, ou algo sendo transportado da mente do "produtor de informação" para a de um usuário, ou ainda, algo alienado de uma subjetividade e convenientemente encapsulado em uma objetividade mensurável, mas é encarada como uma dimensão existencial do homem social, colocado no mundo com os outros, na expressão de Heidegger. A necessidade de informação não é suposta a priori (abordagens físicas) ou expressa como uma funcionalidade do sistema de recuperação de informação (modelo de Belkin e seus colegas), mas nasce de interações entre os atores e os diversos domínios do ambiente.

Como se depreende da análise de Favier e Martin-Juchat (2002), admitir didaticamente uma relativa concentração cronológica dos surgimentos dos tipos de abordagens no campo da Ciência da Informação, traz a vantagem de vislumbrar movimentos em torno do conceito de usuário: sua pré-concepção modelar nas abordagens físicas, a aproximação de um usuário considerado em suas estruturas mentais nas abordagens cognitivistas e, novamente, um afastamento do usuário individualizado nas abordagens pragmáticas para valorizar o "usuário social" criado em uma rede de relacionamentos sociais e históricos.

\section{A B ORDAGENS EMERGENTES}

Entre as inúmeras abordagens que podem ser consideradas emergentes, duas são examinadas. A análise de domínio de Hiorland é intrinsecamente transdisciplinar e faz parte de sua metodologia a consideração dos aspectos sociais, históricos e epistemológicos das comunidades discursivas. A cognição situada é exemplar por renovar os cânones cognitivistas, constituindo uma abordagem integrada.

\section{Análise de domínio}

A abordagem da análise de domínio preceitua que a mais proveitosa atitude para a Ciência da Informação é estudar os domínios do conhecimento como comunidades de discurso ou pensamento, que são partes da divisão do trabalho em uma sociedade. Tratase de uma abordagem social-epistemológica, funcionalista e realista, a qual procura transcender as percepções 
individualistas e subjetivas dos usuários para fundamentar seus princípios e metodologia.

Segundo Capurro (2003a), uma conseqüência prática da análise de domínio é o abandono de uma linguagem ideal de representação do conhecimento ou de algoritmos ideais para a recuperação da informação, que foram metas de muitas abordagens físicas ou cognitivistas. Adquire especial importância o estudo das ligações dos discursos, das áreas do conhecimento $\mathrm{e}$ dos documentos, sob as diversas perspectivas ou pontos de acesso das comunidades de usuários. Procura-se uma integração da perspectiva individualista e isolacionista das abordagens cognitivistas com o contexto social das comunidades. Os conceitos de informação só têm sentido em relação a um pressuposto conhecido e compartilhado entre os diversos membros da comunidade, e é com essa argumentação que Capurro procura destacar os pontos em comum da análise de domínio com a hermenêutica e o conceito de précompreensão.

Um domínio pode ser uma disciplina científica, um campo científico ou uma comunidade discursiva relacionada a um partido político, à religião, ao comércio, dentre outros. Os domínios são normalmente definidos por teorias ontológicas (seus objetos). As dimensões epistemológicas dos domínios dizem respeito aos diferentes modos de conhecimento. As dimensões sociológicas, centrais na análise de domínio, referemse aos diferentes grupos de pessoas estudando os diversos campos de conhecimento. Hiørland $(2004$, p.6) assim resumiu o argumento:

[...] todas as três dimensões são importantes na análise de domínio. A análise de domínio explora relações ontológicas, isto é, relações genéricas em tesauros e sistemas de classificação. Também estuda grupos sociais como cientistas, profissionais, estudantes ou crianças. Final-

A análise de domínio adota um ponto de vista sócio-cognitivo (Hiørland, 2004), onde são valorizados os papéis da cultura e da sociedade na cognição. Em detrimento das representações simbólicas, as pesquisas em semântica e pragmática são enfatizadas, agora considerando as ações como entidades básicas na análise. Em suma, a ênfase é deslocada para a internalização de signos e símbolos socialmente produzidos e no modo pelo qual os processos cognitivos são mediados por significados construídos cultural, histórica e socialmente.

Filosoficamente, é adotada uma visão pragmático-realista. Isso implica dizer que se aceita a existência de uma realidade objetiva, mas não afirmações definitivas sobre alguma verdade, havendo aqui uma aproximação com a teoria da falsificabilidade de Popper. Essa visão implica em uma distinção prática entre conhecimento subjetivo e objetivo, este norteando e configurando as possibilidades do primeiro, assim como um modo de entendimento do conceito de relevância na Ciência da Informação, o qual está orientado a objetivos e propósitos dentro de determinado domínio e baseado em argumentos próprios ao contexto.

Hiørland (2002) descreve onze abordagens, entre tradicionais e inovadoras, para a análise de domínio na Ciência da Informação. As abordagens mais tradicionais são, entre outras, a criação de guias de literatura para áreas específicas, a produção de classificações especializadas e tesauros, estudos bibliométricos e pesquisas em indexação e recuperação de informação. Essas abordagens tradicionais são mediadas por estudos inovadores de linguagem, de gênero, históricos, epistemológicos e críticos nos diversos domínios para a determinação de suas especificidades. Hiørland espera que esses estudos, utilizando uma combinação dessas abordagens, reforcem a identidade da Ciência da Informação, aproximem teoria e prática e promovam um exercício de interdisciplinaridade.

\section{Cognição situada}

A cognição situada abrange diversas abordagens contemporâneas das ciências cognitivas, dentre as quais: Biologia do Conhecer, proposta por Maturana e Varela (2001); Cognição Situada, idealizada por Clancey (1997); Enactive View, desenvolvida por Varela; Thompson; Rosch (1991); e Ecologia da Mente, estabelecida por Bateson (1972). O ponto fundamental que liga essas abordagens é a utilização do mesmo princípio epistemológico na constituição de suas teorias. Tal princípio considera o organismo em seu ambiente, ambos formando um todo inseparável e interagindo constantemente. Assim, não prevalece uma dicotomia sujeito-objeto, já que o mundo é incessantemente reconstruído na dinâmica do viver e a realidade é dependente do observador. 
Venâncio e Borges (2006a) procuraram estabelecer os fundamentos da cognição situada e suas relações com a Ciência da Informação. Se as abordagens cognitivistas consideram os indivíduos processadores de informação, isto é, sistemas abertos que recebem informações, processam-nas e geram saídas, Maturana e Varela (2001) os consideram sistemas fechados informacionalmente e determinados estruturalmente.

Mas o que implica ser fechado informacionalmente? Como os sujeitos vivem em constante interação com o meio, seu viver modula o meio e vice-versa, havendo uma co-modulação e a constituição de um todo imbricado. Enquanto houver essa congruência, condição mesma da existência, haverá perturbações mútuas que desencadearão (ou não) mudanças estruturais. Mas essas mudanças, pelas quais os sujeitos passam em conseqüência de interações, não são especificadas externamente, mas pelas próprias estruturas individuais (determinismo estrutural). Logo, a informação não é "captada" do meio, mas vista como uma possível perturbação da estrutura individual, podendo ou não ser determinada em função da própria estrutura e de sua história de relações com o meio. Assim, nós mesmos especificamos quais configurações do meio serão informações (perturbações), e quais mudanças estas desencadearão em nosso organismo.

$\bigcirc$ conhecer não se reduz à informação processada, oriunda de um mundo anterior à experiência do observador. Não se trata de um processo de acumulação de representações do ambiente, muito menos de cópia da realidade, mas de mudanças estruturais ocorridas no sujeito, as quais são contingentes em sua história de interações com o meio. $\bigcirc$ conhecimento é ação efetiva. Assim, a cognição situada compreende a informação e o conhecimento como construções realizadas pelos sujeitos, a partir das realidades sócio-históricas vivenciadas por eles.

Na teoria, também são ressaltados os papéis fundamentais da linguagem e da emoção. Para Maturana e Varela (2001) e Maturana (1998), a linguagem não é meramente sistema de signos e regras utilizado para a comunicação. Ela é lugar das reflexões e só ocorre no fluxo de coordenações de conduta consensuais recursivas, ou coordenações de coordenações de ação, entre sujeitos. Realizamos tudo na linguagem, guiados por nossas emoções, que são disposições corporais dinâmicas que especificam, a cada momento, os domínios de ação nos quais nos movemos. Não há ação humana (e, portanto, conhecimento) sem emoção que a estabeleça como tal e a torne possível. Só se conhece quando há pré-disposição emocional e interações congruentes na linguagem.

A cognição situada permite repensar os conceitos de informação e conhecimento, por considerar que as possibilidades cognitivas do sujeito residem tanto na sua determinação estrutural e biológica quanto nas suas interações com o meio. Ao mesmo tempo em que vive em contínua interação com os outros, o ser humano vive à deriva de experiências individuais intransferíveis. Tudo aquilo que vivemos, é vivido por nós de uma maneira determinada por nossa estrutura, cuja dinâmica é contingente e historicamente especificada e modulada por nossos encontros em interações coletivas. Assim, essa concepção apóia-se no princípio de que somos simultaneamente seres individuais e sociais, a todo instante, de forma indissociável, o que possibilita a compreensão dos fenômenos de informação como processos sociais, cognitivos e comunicacionais.

No âmbito da Ciência da Informação, predominam os estudos que utilizam princípios da vertente cognitivista. No entanto, começam a surgir estudos que adotam os fundamentos das abordagens cognitivas contemporâneas. Um deles é o estudo das relações da leitura e da cognição, realizado por Dumont (2006); este, com o aporte das teorias de Maturana e Morin, tem como objetivo analisar as implicações do ato de ler, considerado como atribuição de significado e sentido, e os processos que transformam a leitura em conhecimento para o leitor.

Outros trabalhos enfocam ambientes organizacionais como a pesquisa desenvolvida por Borges (2002), que aborda a inteligência competitiva sob o enfoque cognitivo da biologia do conhecer, a partir da observação do ambiente de negócios de proprietários de pequenas e médias empresas, permitindo a compreensão de como se dão as interações entre essas empresas e o seu meio e de como as atividades de inteligência empresarial são estruturadas em função dessas relações. Sob o mesmo enfoque, Pereira e Borges (2006) analisam empresas de pequeno e médio porte do ramo de consultoria empresarial. Outro estudo, proposto por Venâncio e Borges (2006b), tem por objetivo investigar o comportamento de busca de informação de pessoas responsáveis por tomada de decisão, com base nos princípios da cognição situada. 
Para tanto, analisa-se o modo pelo qual as histórias particulares e as disposições emocionais dos decisores, assim como suas histórias de relações com outros sujeitos, influenciam seus comportamentos de busca de informação. Além disso, procura-se compreender como os decisores estabelecem redes de interações e relações com outros sujeitos e de que modo essas redes influenciam os processos de busca de informação.

\section{CONSIDERAÇÕES FINAIS}

A concepção de abordagens para o estudo do campo da Ciência da Informação constitui um procedimento metodológico que procura ser descritivo e indutor de uma perspectiva histórica e epistemológica. Evita-se a valorização de abordagens ou sua instituiç̧ão programática, uma vez que teorias ou projetos do campo não podem ser rigidamente classificados. Eventualmente, percebem-se ênfases em modelos tipicamente compreendidos como físicos, cognitivistas, sociais ou pragmáticos. Usualmente, ocorre uma complementaridade de abordagens e/ou de diversas influências, com maior ou menor explicitação das tendências. Observe-se ainda que uma exposição de abordagens do campo da Ciência da Informação não pode pretender-se estritamente cronológica, bastando atentar-se para a teoria de Shera $(1971,1973)$, que já na década de 70 falava de uma cognição social resultante da orientação dos estudos cognitivos ao incorporar aspectos sociais e vivenciais. Uma periodização é sempre arbitrária, o que fica evidente ao lembrar a "retomada" de antigos paradigmas, como o social, existente na biblioteconomia (Miksa, 1992).

Percebe-se a grande diversidade de temas e objetivos de trabalhos reunidos sob o campo, que utilizam conceitos díspares (inclusive o de informação) ou eventualmente definidos sem rigor. Isso conduz à sugestão de que o campo apresenta-se como um conjunto de problemas, soluções e modelos, e de que muitas vezes converte-se a transdisciplinaridade em incorporação acrítica de teorias de outros campos, sem efetiva coerência ou entrosamento, ou mesmo sem uma saudável atitude de renovação.

Francelin (2004), em um exaustivo estudo epistemológico realizado em periódicos brasileiros da Ciência da Informação com base na identificação de termos relacionados à pós-modernidade, chega à conclusão, entre outras, de que vários termos são utilizados de modo não condizente com o uso em suas fontes originais. Assim, tomando um exemplo, constatou-se que o termo paradigma aparece, nos artigos, dissociado de perspectivas que retomem as revoluções científicas ou o progresso do conhecimento, básicas para o pensamento de Kuhn ou Popper. Há uma valorização dos novos paradigmas no contexto de globalização, explosão informacional, novas tecnologias de informação e comunicação; entretanto, essa valorização ocorre sem a construção de novas metodologias ou conceitos. Nesse sentido, é sintomático que Wersig (1993) tenha começado com a crítica à tentativa de institucionalização de paradigmas no campo, para só então enfrentar um dos problemas centrais: a necessidade de reformulação dos modelos e conceitos do campo. Ao ver do autor, modelos básicos devem ser desenvolvidos por meio da redefinição de conceitos científicos mais amplos (comunicação dando origem à redução da complexidade, por exemplo). Deve haver também uma reformulação científica de interconceitos, ou seja, os utilizados como conceitos ordinários fora da disciplina (como conhecimento ou imagem, por exemplo). Por fim, os interconceitos e modelos devem ser perfeitamente concatenados, sob o prisma evolucionário, sinóptico e transdisciplinar. Mais que uma teoria, a Ciência da Informação funda-se sobre um esquema de trabalho que compreende o entrelaçamento de conceitos científicos gerais, modelos e conceitos ordinários, sob os aspectos de seu desenvolvimento (histórico, a nosso ver) e de sua possível combinação do ponto de vista da resolução de problemas do conhecimento.

A necessidade de melhor delimitação do campo e precisão dos conceitos utilizados é acompanhada pela premência de uma visão mais unificada, com efetivo entrosamento entre as abordagens, de modo a traduzir seus conceitos em forma prática (pragmática, vivencial, situacional). Essa necessidade de integração passa pela retomada, reformulação e combinação de diversas abordagens, inclusive a física. É o que procura fazer Buckland (1991), valorizando a informação-coisa sem a exclusão de suas dimensões processuais e de conhecimento. Também o faz Metzger (2002), destacando a necessidade de um estudo bidimensional da informação-objeto, enquanto entidade autônoma e enquanto objeto construído, transferido e acessado em ambientes sociais, culturais e profissionais, que são os locais de realização de tais operações - nos termos de Foucault, atentando para um regime da materialidade 
que é mais institucional do que espaço-temporal. De maneira semelhante, destaca-se o esforço consubstanciado no denominado Trilema de Capurro (Capurro; 1999; Capurro; Fleissner; Hofrirchner, 1999; 2003a), que busca unificar o conceito de informação explorando as dimensões análogas, equívocas e unívocas de diversas definições pré-existentes.

Reconhecidos os compromissos práticos da Ciência da Informação, discerníveis em suas conceituações, sua história e sua pragmática, adquire grande importância a pluralidade metodológica. Essa pluralidade implica imaginação e criatividade na migração de conceitos e construção de contextos para a recepção de métodos concebidos em outras áreas (Santos, 2002). Para que se consiga estabelecer um modo de trabalho que comporte a diversidade e que procure evitar as tentativas de implantação de para- digmas, a apropriação acrítica de conceitos e modelos ou as disputas paradigmáticas, será útil dar ênfase aos programas de pesquisa (Lakatos, 1970). Esses programas coletivos e institucionalizados agregam indivíduos e organizações, concentram recursos e instituem escolhas metodológicas e heurísticas positivas ou negativas, que delimitam o objeto de estudo do campo (González de Gómez, 2000). O fundamental é que, mais do que nunca, constata-se, no campo da Ciência da Informação, a necessidade da integração de diferentes perspectivas, paradigmas ou abordagens (ou qualquer que seja a denominação utilizada), da tradução, precisão e fundamentação dos conceitos utilizados, da diversificação metodológica e de um viés pragmático que focalize os problemas comuns e soluções adotadas no campo e considere os aspectos culturais, sociais, históricos e epistemológicos.

\section{REFERÊNCIAS}

ARAÚJO, C.A. A pesquisa norte-americana. In: HOHLFELDT, A.; MARTINO, L.C.; FRANÇA, V.V. (Orgs.). Teorias da comunicação: conceitos, escolas e tendências. 3.ed. Petrópolis: Vozes, 2003

BATESON, G. Steps to an ecology of mind. New York: Ballantine Books, 1972.

BELKIN, N.J.; ODDY, R.N.; BROOKS, H.M. ASK for information retrieval: Part I. Background and theory. Journal of Documentation, v.38, n.2, p.61-71, 1982a.

BELKIN, N.J.; ODDY, R.N.; BROOKS, H.M. ASK for information retrieval: Part II. Results of a design study. Journal of Documentation, v.38, n.3, p.145-164, 1982b.

BORGES, M.E.N. A informação e o conhecimento na biologia do conhecer: uma abordagem cognitiva para os estudos sobre inteligência empresarial. 2002. Tese (Doutorado em Ciência da Informação) - Escola de Ciência da Informação, Universidade Federal de Minas Gerais, Belo Horizonte, 2002.

BROOKES, B.C. The foundations of information science: Part I: Philosophical Aspects. Journal of Information Science, v.2, p.125-133, 1980 .

BUCKLAND, M. Information as thing. Journal of the American Society for Information Science, v.42, n.5, p.351-360, 1991.

CAPURRO, R. What is information science for? A philosophical reflection. In: VAKKARI, P.; CRONIN, B. (Eds.). Conceptions of Library and Information Science. London: Taylor Graham, 1992. p.82-96.

CAPURRO, R.; FLEISSNER, P.; HOFKIRCHNER, W. Is a unified theory of information feasible? A Trialogue. In: HOFKIRCHNER, W. (Ed.): The Quest for a Unified Theory of Information. Proceedings of the Second International Conference on the Foundations of Information Science, 1999. p.9-30. Disponível em: <http://www.capurro.de/trialog.htm>. Acesso em: 7 jul. 2006.
CAPURRO, R. Hermeneutics and the phenomenon of information. In: MITCHAM, C. (Ed.). Metaphysics, epistemology, and technology: Research in philosophy and technology. v. 19, JAl/ Elsevier Inc. p.79-85, 2000. Disponível em: <http:// www.capurro.de/ny86.htm >. Acesso em: 7 jul. 2006.

CAPURRO, R. Epistemologia e Ciência da Informação. In: ENCONTRO NACIONAL DE PESQUISA EM CIÊNCIA DA INFORMAÇÃO - ENANCIB, 5., 2003. Belo Horizonte, Anais... Belo Horizonte, 2003a.

CAPURRO, R. Foundations of information science: Review and perspectives. 2003b. Disponível em: <http://www.capurro.de/ tampere91.htm >. Acesso em: 7 jul. 2006.

CLANCEY, W.J. Situated cognition: On human knowledge and computer representations. Cambridge University Press, 1997.

DE MEY, M. The relevance of the cognitive paradigm for information science. In: HARBO, Ole; KAJBERG, (Ed.): Theory and application of information research. London: Mansell, 1980. p.48-61.

DUMONT, L.M.M. Leitura e cognição: possíveis entrelaçamentos. In: ENCONTRO NACIONAL DE PESQUISA EM CIÊNCIA DA INFORMAÇÃO - ENANCIB, 7., 2006, Marília. Anais... Marília, 2006. Disponível em: <http://www.portalppgci.marilia.unesp.br/ enancib/viewabstract. php?id=68>. Acesso em: 16 nov. 2006.

ELLIS, D. Paradigms and proto-paradigms in information retrieval research. In: VAKKARI, P.; CRONIN, B. (Eds.). Conceptions of Library and Information Science. Historical, empirical and theoretical perspectives. London, 1992. p.165-186.

FAVIER, L.; MARTIN-JUCHAT, F. La science de I'information face à de nouveau paradigmes: prise en compte de la dimension sociale de la recherche d'information et remise en cause de la figure de I'usager. In: COUZINET, V et al. (Dir.). Recherches récentes en sciences de l'information: convergences et dynamiques. Actes du colloque international, 2002, L'Université Toulouse 3. Paris: ADBS Éditions, 2002. 
FRANCELIN, M.M. Configuração epistemológica da Ciência da Informação no Brasil em uma perspectiva pós-moderna: análise de periódicos da área. Ciência da Informação, Brasília, v.33, n.2, p. 49-66, 2004.

FROHMANN, B. Knowledge and power in library and information science: Toward a discourse analysis of the cognitive viewpoint. In: VAKKARI, P.; CRONIN, B. (Eds.). Conceptions of Library and Information Science. Historical, empirical and theoretical perspectives. London, 1992. p.135-148.

GONZÁLEZ DE GÓMEZ, M.N. Dos estudos sociais da informação aos estudos do social desde o ponto de vista da informação. In: AQUINO, M.A. (Org.) O campo da Ciência da Informação. Gênese, conexões e especificidades. João Pessoa: Universitária, 2002.

GONZÁLEZ DE GÓMEZ, M.N. Metodologia de pesquisa no campo da Ciência da Informação. DataGramaZero, v. 1, n.6, 2000. Disponível em: <http://www.dgz.org.br/dez00/Art_03. $\mathrm{htm}>$. Acesso em: 16 nov. 2006.

HJØRLAND, B. Domain analysis in information science: Eleven approaches -traditional as well as innovative, Journal of Documentation, v.58, n.4, p.422-462, 2002.

HJØRLAND, B. Domain analysis in information science. In: ENCYCLOPEDIA of Library and Information Science. New York: Marcel Dekker, 2004. p. 1-7. Disponível em: <http://www.dekker. com/servlet/product/DOI/101081EELIS1200249 90>. Acesso em: 7 jul. 2006.

INGWERSEN, P. Cognitive information retrieval. Annual Review of Information Science and Technology (ARIST), v.34, p.3-52, 1999.

KUHN, T.S. A estrutura das revoluções científicas. São Paulo: Editora Perspectiva, 2000.

LAKATOS, I. Falsification and the methodology of scientific research programmes. In: LAKATOS, I.; MISGRAVE, A. (Eds.). Criticism and the growth of knowledge, Cambridge: Cambridge University Press, 1970.

LE COADIC, I.F. A Ciência da Informação. Brasília: Briquet de Lemos, 1996.

MASTERMAN, M. The nature of a paradigm. In: LAKATOS, I.; MISGRAVE, A. (Eds.). Criticism and the growth of knowledge, Cambridge: Cambridge University Press, 1970.

MATHEUS, R.F. Rafael Capurro e a filosofia da informação: abordagens, conceitos e metodologias de pesquisa para a Ciência da Informação. Perspectivas em Ciência da Informação, Belo Horizonte, v. 10, n.2, p. 140-165, 2005.

MATURANA, H.R. A ontologia da realidade. GRACIANO, V.; MAGRO, C.; VAZ, N. (Orgs.). Belo Horizonte: Editora UFMG, 1997.

MATURANA, H.R. Emoções e linguagem na educação e na política. Belo Horizonte: UFMG, 1998.

MATURANA, H.R.; VARELA, F.J. A árvore do conhecimento: as bases biológicas da compreensão humana. São Paulo: Palas Athenas, 2001.

METZGER, J.-P. Les trois pôles de la science de l'information. In: COUZINET, V. et al. Recherches récentes en sciences de I'information: convergences et dynamiques. Actes du colloque international, 2002, I’Université Toulouse 3. Paris: ADBS Éditions, 2002.
MIKSA, F.L. Library and information science: Two paradigms. In: VAKKARI, P., Blaise Cronin (Eds.): Conceptions of Library and Information Science: Historical, empirical and theoretical perspectives. London, 1992. p.229-243.

MIRANDA, A. A Ciência da Informação e a teoria do conhecimento objetivo: um relacionamento necessário. In: AQUINO, M. A (Org.). O campo da Ciência da Informação: gênese, conexões e especificidades. João Pessoa: Universitária, 2002.

PEREIRA, F.C.M.; BORGES, M.E.N. A inteligência empresarial e a biologia do conhecer: uma análise exploratório-qualitativa do setor de pequenas e médias empresas de consultoria de Belo Horizonte. Encontros Bibli - Revista Eletrônica de Biblioteconomia e Ciência da Informação, n.22, 2006. Disponível em: <http:// www.encontros-bibli.ufsc.br/Edicao_22/pereira.pdf>. Acesso em: 16 nov. 2006.

POPPER, K. A lógica da pesquisa científica. São Paulo: Cultrix, 2000.

SANTOS, B.S. Um discurso sobre as ciências. 13.ed. Porto: Afrontamento, 2002.

SARACEVIC, T. Ciência da Informação: origem, evolução, relações. Perspectivas em Ciência da Informação, v. 1, n. 1, p.41-62, 1996.

SHANNON, C.E. A mathematical theory of communication. The Bell System Technical Journal, v.27, p.379-423, 623-656, 1948.

SHERA, J. The sociological relationships of information science. Journal of the American Society for information Science, v.22, n. 1, p.76-80, 1971.

SHERA, J. Toward a theory of librarianship and information science. Ciência da Informação, Rio de Janeiro, v.2, n.2, p.87-97, 1973.

TAYLOR, R.S. Information use environment. In: DERVIN, B.; VOIGT, M.J. (Ed.). Progress in Communication Sciences, v. 10, p. 217. $255,1991$.

TAYLOR, R.S. Value-added process in the information life cycle. Journal of the American Society for Information Science (JASIS), v.33, n.5, p.341-346, 1982.

VAKKARI, P., CRONIN, B. (Eds.). Conceptions of library and Information Science: historical, empirical and theoretical perspectives. London: Taylor Graham, 1992.

VARELA, F.; THOMPSON, E.; ROSCH, E. The embodied mind: cognitive science and human experience. Cambridge: MIT Press, 1991. 308p.

VENÂNCIO, L.S.; BORGES, M.E.N. Cognição situada: fundamentos e relações com a Ciência da Informação. Encontros Bibli - Revista Eletrônica de Biblioteconomia e Ciência da Informação, n.22, 2006a. Disponível em: < http://www.encontrosbibli.ufsc.br/Edicao_22/venancio.pdf>. Acesso em: 16 nov. 2006.

VENÂNCIO, L.S.; BORGES, M.E.N. O caminhar faz a trilha: o comportamento de busca de informação sob o enfoque da cognição situada. In: ENCONTRO NACIONAL DE PESQUISA EM CIÊNCIA DA INFORMAÇÃO - ENANCIB, 7., 2006b. Marília. Anais... Marília, 2006b. Disponível em: <http://www.portalppgci. marilia.unesp.br/enancib/viewabstract. php?id=267>. Acesso em: 16 nov. 2006.

WERSIG, G. Information Science: The study of postmodern knowledge usage. Information Processing and Management, v.29, n.2, p.229-239, 1993. 